\title{
Regional influences of the Fallopian tubes on the rate of boar sperm capacitation in surgically inseminated gilts
}

\author{
R. H. F. Hunter*, W. T. Huang and W. Holtz \\ Institute of Animal Physiology and Genetics, University of Göttingen, Albrecht-Thaer-Weg 3, D-37075 Göttingen, Germany
}

\begin{abstract}
Aliquots of ejaculated boar semen containing known numbers of spermatozoa were deposited into the caudal isthmus or rostral ampulla of the Fallopian tubes of gilts at, or immediately after, ovulation to assess regional influences on the rate of capacitation. Eggs were recovered during a second intervention $4,5,6$ or $7 \mathrm{~h}$ after surgical insemination and were examined by phase-contrast microscopy. Results were obtained from ten animals in each of the 4-, 5- and 6-h groups and from eight animals in the 7-h group. With two exceptions, fertilized eggs were not recovered until $6 \mathrm{~h}$ after insemination into the isthmus, the proportion (45.6\%) being significantly greater than the corresponding figure $(1.4 \%)$ for ampullary insemination $(P<0.001)$. Similarly, the proportion of fertilized eggs recovered $7 \mathrm{~h}$ after insemination into the isthmus $(58.7 \%)$ was significantly greater than after ampullary insemination $(21.9 \% ; P<0.01)$. Numbers of spermatozoa associated with the zona pellucida remained low in all these instances, with mean figures per egg ranging from 0.3 to 3.8 . Insemination into the isthmus gave a 1-2 $\mathrm{h}$ advantage in fertilization compared with insemination into the ampulla. Although relative rates of sperm cell progression to the site of fertilization may have contributed to this, there is strong evidence that rates of capacitation differ significantly in the respective portions of the Fallopian tube. Therefore, attention was focused on: (1) the viscous glycoprotein secretion in the caudal isthmus acting to remove seminal plasma from the sperm surface; and (2) the phase of sperm head binding to the isthmus epithelium. Gradients in local endocrine modulation by the adjacent ovary offer one explanation for the functional specialization of different regions of the Fallopian tubes.
\end{abstract}

\section{Introduction}

Definitions of the process of capacitation appear frequently in the literature, even though details of the underlying cellular modifications are not clear. Definitions usually concern the period of residence in the female tract before spermatozoa can attach to and penetrate the zona pellucida of recently ovulated eggs (Austin, 1951; Chang, 1951). An alternative definition refers to changes in the sperm cell that precede and permit a coordinated acrosome reaction (Bedford, 1970; Chang and Hunter, 1975). Both approaches focus principally on the sperm cell rather than on interactions between spermatozoa and the female tract. Furthermore, recent studies have moved largely to in vitro experimentation in an attempt to characterize molecular modifications in spermatozoa completing the process of capacitation. As an alternative to the in vitro approach the technique of surgical insemination of quantified sperm populations into particular portions of the genital tract has been used. Such studies take into account the following: (1)

\footnotetext{
* Present address and for correspondence: Department of Clinical Studies Reproduction, Royal Veterinary and Agricultural University, Bülowsvej 13, 1870 Frederiksberg C, Copenhagen, Denmark.

Received 28 September 1997.
}

the coordinating role of the female tract in sperm surface modifications (Yanagimachi, 1994); (2) a local influence of ovarian endocrine programming on specific regions of the Fallopian tube epithelium (Hunter et al., 1983; Hunter, 1995a); and (3) the intimate endosalpingeal-sperm head interactions in the hours before ovulation (Racey et al., 1975; Fléchon and Hunter, 1981; Hunter et al., 1987, 1991; Suarez, 1987; Smith and Yanagimachi, 1990, 1991; Pollard et al., 1991). Furthermore, the in vivo approach recognizes that completion of the process of capacitation is a periovulatory event (Hunter, 1987a,b; Smith and Yanagimachi, 1989). These studies suggest that at least the final stages of capacitation are programmed by ovarian cues, almost certainly of an endocrine nature, although they are modulated by the endosalpinx.

Previous studies have demonstrated regional variations in the capacitating potential of the female reproductive tract, suggesting that there are synergistic influences between the uterus and Fallopian tubes in the capacitation of spermatozoa (Adams and Chang, 1962; Bedford, 1968, 1969; Hunter, 1969; Hunter and Hall, 1974). In the present study, surgical insemination was used to examine regional influences on the rate of capacitation in boar spermatozoa exposed only to the Fallopian tubes. The ampullary and isthmic regions of the pig 
Fallopian tube differ in morphology (Andersen, 1927; Hafez and Blandau, 1969), epithelial folding and organization of surface organelles (Stalheim et al., 1975; Wu et al., 1976; Fléchon and Hunter, 1981), vascular arcade and lymphatic bed (Andersen, 1927; Hunter, 1988), luminal and surface temperatures (Hunter and Nichol, 1986; Hunter et al., 1997), and the composition of luminal fluids (Hunter, 1990; Nichol et al., 1992, 1997). Therefore, it is reasonable to anticipate that different rates of capacitation will occur in the different regions. In the present study, observation was made of the ability of spermatozoa to penetrate the egg investments and prompt activation of the secondary oocytes. In a parallel study (Hunter $e t$ al., unpublished), different regions of the pig endosalpinx were examined for the presence of particular classes of mRNA that encode macromolecules involved in capacitation. The overall premise was that the more precisely defined the physiological circumstances under which capacitation occurs in the Fallopian tubes, the more meaningful and rigorous the corresponding molecular interpretation would be.

\section{Materials and Methods}

\section{Animals}

Pigs were obtained from the University of Göttingen experimental farm, Relliehausen, at approximately 5.5-7.0 months of age and close to the onset of puberty. They were crossbred Large White $\times$ Landrace and weighed between 80 and $112 \mathrm{~kg}$. The animals were housed in indoor pens at the institute in groups of four-six. Natural daylight was supplemented by artificial light during the winter months. Animals were bedded on straw, fed a standard commercial diet of pelletted concentrates, and had free access to drinking water. None of the animals had previously been subjected to any form of insemination or other experimental procedure.

\section{Ovarian stimulation}

A well-established technique of inducing ovulation at a predetermined time was used in these experiments (Holtz, 1996). Each animal received a single subcutaneous injection of 1000 iu pregnant mares' serum gonadotrophin (PMSG) (Intergonan; Intervet, Toenisvorst) followed $78-82 \mathrm{~h}$ later by a single injection of 500 iu hCG (Ovogest; Intervet, Toenisvorst). Ovulation was expected approximately $41-42 \mathrm{~h}$ after the hCG injection, a response that was verified at surgery. Vulval swelling and reddening occurred after the PMSG injection, usually in conjunction with oestrous behaviour and standing oestrus.

\section{Semen samples}

Freshly collected semen from boars of proven fertility (used as commercial artificial insemination sires) was provided by the Veterinary Institute, University of Göttingen. Aliquots of whole semen, filtered free of the gelatinous bulbourethral secretion, were transferred to the operating theatre in a Dewar flask prewarmed to a temperature of $35^{\circ} \mathrm{C}$. Pasteur glass pipettes, microscope slides and coverslips were used at $37^{\circ} \mathrm{C}$ to examine and evaluate microdroplets of the sperm suspension by phase-contrast microscopy for progressive motility. They were scored on a subjective scale of $1-5 ; 5$ representing the best motility. Only those samples scoring at least 3 in this assessment were used in the experiment. After suitable dilution $(\times 100)$, the sperm concentration was estimated in a haemocytometer slide (Neubauer ruling). The range in concentration of the inseminated samples was $2.21-3.87 \times 10^{8}$ cells $\mathrm{ml}^{-1}$.

\section{Surgical intervention and insemination}

Animals were starved for $12 \mathrm{~h}$ before surgery and then given a $5 \mathrm{ml}$ intramuscular injection of the preoperative sedative Stresnil (Azaperone, $40 \mathrm{mg} \mathrm{ml}^{-1}$; Janssen, Neuss) followed $15 \mathrm{~min}$ later by intravenous administration of $10 \mathrm{ml}$ Hypnodil (Metomidathydrochloride, $50 \mathrm{mg} \mathrm{ml}^{-1}$; Janssen, Neuss). This intravenous anaesthetic was supplemented as required to maintain full surgical relaxation.

The reproductive organs were exposed during a midventral laparotomy and the ovaries were examined briefly for the presence of recent ovulations. Individual Fallopian tubes were then withdrawn for surgical insemination with an absolute minimum of handling. On one side of the tract, $0.02 \mathrm{ml}$ of the sperm suspension was introduced into the caudal tip $(0.5 \mathrm{~cm})$ of the isthmus using a polished (roundtipped) $2.2 \mathrm{~cm} \times 20$ or 21 gauge needle attached to a $1.0 \mathrm{ml}$ sterile disposable syringe (Sabre; Gillette Surgical, Isleworth). The needle was inserted into the lumen of the isthmus by puncturing the adjacent uterine wall and carefully negotiating through the swollen processes of the utero-tubal junction. Both needle and syringe were prewarmed to $37^{\circ} \mathrm{C}$ before removal of the sperm suspension from the Dewar flask. The suspension was introduced into the caudal isthmus with minimal disturbance of the luminal contents. This side of the tract was identified with a fine silk ligature placed in the wall of the corresponding uterine horn.

The contralateral side of the tract was inseminated into the rostral portion of the ampulla. The same syringe and needle, wiped clean with a sterile surgical gauze, was used to deposit $0.02 \mathrm{ml}$ of the same sperm suspension to a depth of 1-2 cm into the ampulla. The lumen of the ampulla was accessed by displacing the fimbriated extremity and introducing the needle without tearing the epithelium. Immediately after this insemination, the fimbriated folds were replaced around the ovary, the reproductive tract was restored to the abdomen, and the incision closed in three layers with continuous sutures. These surgical manipulations routinely occupied less than $20 \mathrm{~min}$. Aseptic procedures were followed throughout. Animals were left to regain consciousness in a straw-bedded pen adjoining the operating theatre. 


\section{Recovery of eggs and closure of abdomen}

Animals were tranquillized and anaesthetized as described earlier 15-20 min before egg recovery at 4, 5, 6 or $7 \mathrm{~h}$ after insemination. The reproductive tract was exposed and the number of recent ovulations was noted. After transection at the utero-tubal junction, the caudal $4-5 \mathrm{~cm}$ of each isthmus was liberated from the supporting mesosalpinx by blunt dissection using intermittent puncture sites made with the outside edges of a pair of fine scissors in the mesentery immediately adjoining the isthmus, followed by controlled digital tearing (Hunter and Dziuk, 1968). Haemostats were briefly applied to the cut edge of the mesosalpinx, and all surface blood was absorbed with surgical gauze. The freed end of the isthmus was introduced into the neck of a $100 \mathrm{ml}$ glass cylinder, and the dissected portion of the tube supported on surgical gauze. Each Fallopian tube was flushed from the ovarian end with $40 \mathrm{ml}$ of PBS $(290 \mathrm{mOsmol})$ or physiological saline at $37^{\circ} \mathrm{C}$ using a disposable hypodermic syringe and a polished (blunted) $4.5 \mathrm{~cm} \times 14$ gauge needle introduced into the rostral portion of the ampulla. These flushings were decanted into sterile tissue culture dishes of $9 \mathrm{~cm}$ diameter, and then searched systematically for eggs under a Wild stereo-zoom dissecting microscope.

The ovaries were checked a second time for the number of ovulations, after which the reproductive tract was cleansed of surface blood, moistened with physiological saline, and restored to the abdomen. The incision was closed in three layers: a continuous suture of No. 3 Mersilk (Ethicon Ltd, Edinburgh) was used in the peritoneum and interrupted sutures of No. 6 Mersilk (Ethicon Ltd, Edinburgh) were used to close the body wall and skin. All animals recovered from surgery without incident.

\section{Mounting and examination of eggs}

Whole mounts were made of the recovered eggs between slide and coverslip supported on pillars of a mixture of paraffin wax and petroleum jelly (Chang, 1952). After a detailed examination for spermatozoa on or in the zona pellucida, eggs were fixed for $24-48 \mathrm{~h}$ in $25 \%$ acetic alcohol (1:3 glacial acetic acid:ethanol), immersed briefly in $100 \%$ ethanol, and stained with $1 \%$ orcein in $45 \%$ acetic acid. This final step, performed under a phase-contrast microscope, induced a gradual swelling and then protracted dissolution of the zona pellucida, enabling an accurate count to be made of the number of surface-associated spermatozoa or those with heads embedded in the zona substance. Nuclear structures in the stained preparations were subsequently examined and recorded. Eggs activated by a spermatozoon in the vitellus are referred to as fertilized.

\section{Experimental design and statistical analysis}

Aliquots of the same sperm suspension were introduced into either the caudal isthmus or rostral ampulla of Fallopian tubes during, or immediately after, ovulation. The side of the reproductive tract for each insemination was chosen in an arbitrary manner. Results were analysed by the chi-squared test.

\section{Results}

\section{Animals not included in analysis}

Sixty-two animals were allocated to the experiment but 24 of these failed to give results that could be included in the analysis. They were found at surgery to be unsuitable for the experiment: 11 were already in the luteal phase of the oestrous cycle with well-developed corpora lutea and had reached puberty before the start of treatment; six had ovulated in only one ovary, thereby preventing a comparison between the two insemination treatments; three had haemorrhagic cystic follicles $(13-20 \mathrm{~mm}$ diameter) as a response to PMSG; three had not ovulated at the time of second laparotomy; and in one animal no eggs were recovered from the flushed tubes.

\section{Ovulation and egg recovery}

As noted at laparotomy, 30 of the 38 animals (78.9\%) included in the results had just completed ovulation at the time of surgical insemination; the remaining eight animals were in the middle of ovulation during the first intervention. Ovulation was complete by the second intervention.

The mean number of ovulations in these animals was 12.7, 13.2, 14.0 and 11.1 for the 4-, 5-, 6- and 7-h groups, respectively (Table 1). The proportion of eggs recovered varied from 87.6 to $93.6 \%$, the overall mean being $90.2 \%$ (Table 1).

\section{Number of zona spermatozoa}

Phase-contrast examination of whole-mount preparations failed to show whether binding of spermatozoa to the zona pellucida had occurred, as distinct from simply surface contact. However, in the results presented below, initial binding or penetration seem probable since spermatozoa were not displaced by the fixation and staining procedures.

In the 4-h group, three instances of insemination into the isthmus yielded eggs with zona spermatozoa, but spermatozoa were not seen on or in the zona pellucida of eggs after ampullary insemination (Table 2). Among the 5-h group, five of the isthmic inseminations yielded zona spermatozoa and four of these five animals also yielded zona spermatozoa after ampullary insemination. Within the 6-h group, seven of the isthmic inseminations resulted in zona spermatozoa compared with four of the ampullary inseminations. In the $7-\mathrm{h}$ group, five of the eight inseminations into the isthmus resulted in zona spermatozoa and five ampullary inseminations also gave zona spermatozoa.

The proportion of eggs possessing zona spermatozoa showed an increasing trend with interval from insemination 
Table 1. The number of gilts yielding eggs from both Fallopian tubes, the total number of ovulations and the proportion of eggs recovered at four different intervals after surgical insemination

\begin{tabular}{lcccc}
\hline \multirow{2}{\text{Intervalfromsurgical}}{$\begin{array}{l}\text { insemination to egg } \\
\text { recovery (h) }\end{array}$} & Number of animals & Number of ovulations & Eggs recovered \\
\cline { 3 - 5 } & 10 & 127 & 113 & 88.9 \\
4 & 10 & 132 & 118 & 89.4 \\
5 & 10 & 140 & 131 & 93.6 \\
6 & 8 & 89 & 78 & 87.6 \\
7 & 38 & 488 & 440 & 90.2 \\
Total & & & & \\
\hline
\end{tabular}

Table 2. The number of eggs with spermatozoa on or in the zona pellucida at four intervals after surgical insemination into the caudal isthmus or the rostral ampulla of the Fallopian tubes of gilts at ovulation

\begin{tabular}{|c|c|c|c|c|c|c|c|c|c|c|}
\hline \multirow{3}{*}{$\begin{array}{l}\text { Interval from } \\
\text { surgical } \\
\text { insemination } \\
\text { to egg } \\
\text { recovery }(h)\end{array}$} & \multicolumn{5}{|c|}{ Insemination into isthmus } & \multicolumn{5}{|c|}{ Insemination into ampulla } \\
\hline & \multirow{2}{*}{$\begin{array}{l}\text { Number of } \\
\text { tubes yielding } \\
\text { eggs with zona } \\
\text { spermatozoa }\end{array}$} & \multirow{2}{*}{$\begin{array}{l}\text { Number of } \\
\text { eggs } \\
\text { examined }\end{array}$} & \multirow{2}{*}{$\begin{array}{l}\text { Number of } \\
\text { eggs with } \\
\text { spermatozoa }\end{array}$} & \multicolumn{2}{|c|}{$\begin{array}{l}\text { Number of } \\
\text { spermatozoa } \\
\text { per egg }\end{array}$} & \multirow{2}{*}{$\begin{array}{l}\text { Number of } \\
\text { tubes yielding } \\
\text { eggs with zona } \\
\text { spermatozoa }\end{array}$} & \multirow{2}{*}{$\begin{array}{l}\text { Number of } \\
\text { eggs } \\
\text { examined }\end{array}$} & \multirow{2}{*}{$\begin{array}{l}\text { Number of } \\
\text { eggs with } \\
\text { spermatozoa }\end{array}$} & \multicolumn{2}{|c|}{$\begin{array}{c}\text { Number of } \\
\text { spermatozoa } \\
\text { per egg }\end{array}$} \\
\hline & & & & Range & Mean & & & & Range & Mean \\
\hline 4 & 3 & 55 & $15^{\mathrm{a}}$ & $3-9$ & 3.8 & 0 & 58 & $0^{\mathrm{b}}$ & 0 & 0 \\
\hline 5 & 5 & 59 & $14^{a}$ & $1-4$ & 0.6 & 4 & 59 & $7^{\mathrm{b}}$ & $1-3$ & 0.3 \\
\hline 6 & 7 & 57 & $35^{a}$ & $1-6$ & 1.5 & 4 & 74 & $6^{\mathrm{b}}$ & $1-2$ & 1.2 \\
\hline 7 & 5 & 46 & $29^{\circ}$ & $1-6$ & 2.6 & 5 & 32 & $12^{\mathrm{d}}$ & $1-3$ & 1.0 \\
\hline Total & 20 & 217 & 93 & $1-9$ & - & 13 & 223 & 25 & $0-3$ & - \\
\hline
\end{tabular}

Statistical significance was assessed by the chi-squared test.

Values with superscripts $a$ and $b$ are significantly different, $P<0.001$.

Values with superscripts $\mathrm{c}$ and d are significantly different, $P<0.05$.

until recovery, especially in the ampullary group, although the mean number of zona spermatozoa was lower after insemination into the ampulla (Table 2).

There was no detectable correlation between the number of spermatozoa inseminated and the number of zona spermatozoa in the corresponding Fallopian tubes, or with the proportion of eggs activated in each insemination group.

\section{Activation and development of eggs}

The proportion of eggs activated by a penetrated spermatozoon, referred to here as fertilized, was analysed according to the interval between insemination and egg recovery (Table 3 ).

Only one fertilized egg was recovered from each of the groups examined 4 and $5 \mathrm{~h}$ after isthmic insemination compared with 26 fertilized eggs in the group examined $6 \mathrm{~h}$ after a comparable insemination $(P<0.001)$. The proportion of fertilized eggs recovered 4 and $5 \mathrm{~h}$ after isthmic insemination ( 1.8 and $1.7 \%$, respectively) was similar to the proportion of fertilized eggs recovered $6 \mathrm{~h}$ after ampullary insemination $(1.4 \%)$. However, the latter figure is significantly different $(P<0.001)$ from the corresponding proportion $(45.6 \%)$ of fertilized eggs recovered $6 \mathrm{~h}$ after isthmic insemination. The proportion of fertilized eggs recovered $7 \mathrm{~h}$ after isthmic insemination $(58.7 \%)$ was significantly greater than the proportion recovered $7 \mathrm{~h}$ after ampullary insemination $(21.9 \% ; P<0.01)$. These results show that insemination of ejaculated spermatozoa into the isthmus gives a $1-2 \mathrm{~h}$ advantage in the timing of fertilization compared with insemination into the ampulla.

Eggs activated by a fertilizing spermatozoon invariably had chromosomes arranged at late anaphase or, more frequently, telophase on the second meiotic spindle. Such eggs always contained an enlarged sperm head with detached mid-piece and at least a proportion of discernible flagellum. Well-formed pronuclei were distinguishable in nine eggs recovered $7 \mathrm{~h}$ after isthmic insemination, but were not observed in the ampullary insemination group. Polyspermic penetration of the vitellus was not detected in this study, but two primary oocytes were recovered. These had a large peripheral germinal vesicle, but no attached or penetrated spermatozoa.

\section{Discussion}

The most important finding of this study is that when identical aliquots of the same boar semen sample are inseminated into the Fallopian tubes at, or immediately after, ovulation, spermatozoa introduced into the caudal tip of the 
Table 3. The proportion of fertilized eggs recovered at four intervals after surgical insemination into the caudal isthmus or rostral ampulla of the Fallopian tubes of gilts at ovulation

\begin{tabular}{|c|c|c|c|c|c|c|c|}
\hline \multirow{2}{*}{$\begin{array}{l}\text { Interval from } \\
\text { surgical } \\
\text { insemination } \\
\text { to egg } \\
\text { recovery }(h)\end{array}$} & \multirow[b]{2}{*}{$\begin{array}{l}\text { Number of } \\
\text { animals }\end{array}$} & \multicolumn{3}{|c|}{ Insemination into caudal isthmus } & \multicolumn{3}{|c|}{ Insemination into rostral ampulla } \\
\hline & & $\begin{array}{l}\text { Number of } \\
\text { eggs } \\
\text { collected }\end{array}$ & $\begin{array}{c}\text { Number of } \\
\text { fertilized eggs }\end{array}$ & Percentage & $\begin{array}{l}\text { Number of } \\
\text { eggs } \\
\text { collected }\end{array}$ & $\begin{array}{l}\text { Number of } \\
\text { fertilized eggs }\end{array}$ & Percentage \\
\hline 4 & 10 & 55 & 1 & $1.8^{\mathrm{a}}$ & 58 & 0 & $0^{\text {a }}$ \\
\hline 5 & 10 & 59 & 1 & $1.7^{\mathrm{a}}$ & 59 & 0 & $0^{\text {a }}$ \\
\hline 6 & 10 & 57 & 26 & $45.6^{\mathrm{b}}$ & 74 & 1 & $1.4^{\mathrm{a}}$ \\
\hline 7 & 8 & 46 & 27 & $58.7^{\mathrm{bc}}$ & 32 & 7 & $21.9^{\mathrm{bd}}$ \\
\hline Total & 38 & 217 & 55 & 25.3 & 223 & 8 & 3.6 \\
\hline
\end{tabular}

Statistical significance was assessed by the chi-squared test. Values with superscripts $a$ and $b$ are significantly different, $P<0.001$.

Values with superscripts $c$ and $d$ are significantly different, $P<0.01$.

isthmus are able to penetrate and activate oocytes 1-2 h earlier than those introduced into the rostral ampulla of the contralateral tube. Although the relative rates of sperm progression to the site of fertilization could be a factor contributing to this difference, there is evidence to suggest that rates of capacitation differ significantly in the respective portions of the Fallopian tubes.

Introduction of sperm suspensions into the Fallopian tube ampulla permits fertilization in various species of mammal. Indeed, this was the original approach used in classical studies of capacitation in rabbits (Chang, 1951; Noyes, 1953) and is also known to be effective in pigs (Polge, 1978). In addition, insemination by the intraperitoneal route has been successful in many mammals (rabbit: Dauzier and Thibault, 1956; Hadek, 1958; Rowlands, 1958; Adams, 1969; guineapig: Rowlands, 1957; cow: Skjerven, 1955; pig: Hunter, 1978), and can lead to $70 \%$ fertilization in pigs if performed close to ovulation (Hunter, 1978). We would expect the ampullary insemination in the present study to be successful because transport systems in the isthmus and ampulla function in opposing directions at, and shortly after, ovulation to displace male and female gametes towards the site of fertilization (Hafez and Blandau, 1969; Hunter, 1977). Although the rate of movement of competent spermatozoa down the ampulla has not been determined, the movement of newly ovulated or transplanted eggs to the site of fertilization requires 6-15 $\mathrm{min}$ in cats and rabbits (Harper, 1961a,b; Blandau, 1969) and no more than 30-45 min in pigs (Oxenreider and Day, 1965; Hunter, 1974). Therefore, it is unlikely that motile spermatozoa would require a period of hours to complete the same movement, especially if introduced directly into the ampulla. Indeed, in this study small numbers of spermatozoa were associated with some eggs $5 \mathrm{~h}$ after insemination.

The temporal advantage gained by boar spermatozoa inseminated into the caudal tip of the isthmus may be partly explained by the viscous glycoprotein secretion that occludes this portion of the duct in oestrous animals before ovulation (Fléchon and Hunter, 1981; Hunter et al., 1987; Hunter, $1995 \mathrm{a}, \mathrm{b})$. One function of this viscous plug in mated animals is to prevent the entry of uterine fluid and suspended polymorphonuclear leucocytes into the Fallopian tubes. Before the progressive destabilization that permits a coordinated acrosome reaction can occur, seminal plasma is displaced from the sperm plasmalemma (Bedford, 1970; Chang and Hunter, 1975). Under physiological conditions, the oedematous polypoid processes at the utero-tubal junction exclude the bulk of seminal plasma from the Fallopian tubes (Du Mesnil du Buisson and Dauzier, 1955; Hunter et al., 1972; Hunter, 1973), even though constituents of the male secretions can still be detected in the tubes of artificially inseminated animals (Einarsson et al., 1980). Subsequent interactions with the viscous glycoprotein ('mucus plug') are a fine-tuning system involved with preovulatory sperm storage in the isthmus (Hunter, 1981, 1984) and preparation for a periovulatory acrosome reaction (Hunter, 1987a,b). The much larger lumen of the ampulla is not occluded by similar viscous material, so a rapid 'filtering' of spermatozoa from the male secretions would not be anticipated.

As is the case for laboratory species such as mice (Suarez, 1987) and hamsters (Smith and Yanagimachi, 1990, 1991), the heads of boar spermatozoa become intimately engaged with the epithelium of the isthmus during the preovulatory interval (Fléchon and Hunter, 1981; Hunter et al., 1987) or in vitro (Suarez et al., 1991). This is referred to as sperm adhesion or sperm binding and it makes an important contribution to the formation of the sperm reservoir and the establishment of a sperm gradient along the isthmus to the site of fertilization. Indeed, the sperm gradient itself may enable more subtle molecular and ionic interactions between limited numbers of spermatozoa and progressive regions of the endosalpinx. In addition, an intimate relationship between the sperm head and the genital tract may stimulate the synthesis of new classes of macromolecules by epithelial cells (Ellington et al., 1993) and, directly or indirectly, permit further modification and remodelling of the sperm head surface membranes. The possible involvement of locally high progesterone concentrations, $\mathrm{Ca}^{2+}$ ion transfer, or even catecholamines on such spermatozoa bound in the isthmus 
has been considered in some detail (Hunter et al., 1983; Hunter, 1995a, 1996, 1997). As a result of sperm head-epithelial binding in the isthmus, spermatozoa may gain temporal advantages in completion of capacitation compared with spermatozoa introduced directly into the ampulla. Lectin binding sites differ between the two regions of the duct epithelium (Raychoudhury et al., 1993), even though spermatozoa can bind in the ampulla.

Chronological aspects of sperm capacitation during passage along the female tract or within particular portions of the tract deserve attention. Way et al. (1997) reported more effective capacitation of bull spermatozoa in vitro when incubated in isthmus fluids compared with ampullary fluids, as judged by subsequent spermatozoon-egg binding. Similarly, more effective induction of the acrosome reaction was reported with isthmic fluid (Grippo et al., 1995). Although Thibault (1959) and Hancock (1961) both suggested that boar spermatozoa require $5-6 \mathrm{~h}$ for capacitation in vivo, Hunter and Dziuk (1968) demonstrated that peri- or postovulatory intracervical insemination enabled pig eggs to be penetrated and activated within $3 \mathrm{~h}$. In a subsequent analysis of regional contributions to the process of capacitation, Hunter and Hall (1974) found that the uterus and Fallopian tubes acted synergistically to promote capacitation of boar spermatozoa within $3 \mathrm{~h}$ of mating. In contrast, when freshly ejaculated boar spermatozoa were introduced directly into the isthmus, capacitation required $5-6 \mathrm{~h}$, as endorsed by the current study. This $2-h$ period of retardation was shown to be due to the presence of whole seminal plasma deposited in the Fallopian tubes at insemination. This finding was later highlighted using suspensions of epididymal spermatozoa (Hunter et al., 1978). Boar epididymal plasma prepared from the caudal region of the duct retarded capacitation of sperm suspensions from the corpus epididymidis by approximately $2 \mathrm{~h}$ when it accompanied surgical insemination directly into the isthmus. This delay was considered to be the period of time required to remove male secretions from the lumen of the isthmus by absorption, dilution and/or metabolism before subtle modification of the sperm surface that would allow the completion of capacitation and membrane destabilization could occur.

In conclusion, the present work suggests that the isthmus is more effective in 'neutralizing' seminal plasma components than the ampulla. This is perhaps surprising, considering the extensive undulations of the ampullary mucosa and epithelium, and its prominent vascular bed in oestrous animals, but may reflect the complex lymphatic network bordering the caudal isthmus (Andersen, 1927). However, significant questions remain as to: (1) precisely what rate-limits the number of spermatozoa completing capacitation at any one time (Hunter, 1995a); (2) how such consistent timing is achieved between animals and between experiments; and (3) the location of this timing programme. Does it lie principally in the sperm cell or is it generated by specific interactions between spermatozoa, the endosalpinx and the luminal fluids? Our current molecular approach (B. Brenig et al., unpublished) to the regional synthesis of macromolecules should clarify these questions.
The authors are grateful to S. Wallenhorst for arranging the supply of animals, to Helma Füllgrabe and Gerardo Padilla for assisting with the surgery, and to the Institute staff for pre- and postoperative care of the animals. Colleagues at the Veterinary Institute, University of Göttingen, supplied freshly collected boar semen, and Birgit Sohnrey supervised the laboratory arrangements. This study was made possible by the award of an Alexander von Humboldt Prize Professorship in Veterinary Physiology to R. H. F. Hunter. Frances Anderson kindly typed the manuscript in Edinburgh.

\section{References}

Adams CE (1969) Intraperitoneal insemination in the rabbit fournal of Reproduction and Fertility $18333-339$

Adams CE and Chang MC (1962) Capacitation of rabbit spermatozoa in the Fallopian tube and in the uterus Journal of Experimental Zoology 151 159-166

Andersen DH (1927) Lymphatics of the Fallopian tube of the sow Contributions to Embryology Carnegie Instifution 19 135-148

Austin CR (1951) Observations on the penetration of the sperm into the mammalian egg Australian Journal of Biological Sciences Series B 4 581-596

Bedford JM (1968) Importance of the Fallopian tube for capacitation in the rabbit Proceedings of 6 th International Congress on Animal Reproduction, Paris 1 35-37

Bedford JM (1969) Limitations of the uterus in the development of the fertilizing ability (capacitation) of spermatozoa Journal of Reproduction and Fertility Supplement 8 19-26

Bedford JM (1970) Sperm capacitation and fertilisation in mammals Biology of Reproduction Supplement 2 128-158

Blandau RJ (1969) Gamete transport - comparative aspects. In The Mammalian Oviduct pp 129-162 Eds ESE Hafez and RJ Blandau. University of Chicago Press, Chicago, IL

Chang MC (1951) Fertilising capacity of spermatozoa deposited into the Fallopian tubes Nature 168697

Chang MC (1952) Fertilisability of rabbit ova and the effects of temperature in vitro on their subsequent fertilisation and activation in vivo. Journal of Experimental Zoology 121 351-382

Chang MC and Hunter RHF (1975) Capacitation of mammalian sperm: biological and experimental aspects. In Handbook of Physiology Ch. 16 Endocrinology V pp 339-351 Eds DW Hamilton and RO Greep. American Physiological Society, Washington

Dauzier L and Thibault C (1956) Recherche expérimentale sur la maturation des gametes mâles chez les mammifères, par l'étude de la fécondation in vitro. Proceedings of 3 rd International Congress on Animal Reproduction, Cambridge 158-61

Du Mesnil du Buisson F and Dauzier L (1955) La remontée des spermatozoides du verrat dans le tractus de la truie en oestrus Comptes Rendus Séances Societé de Biologie 149 76-79

Einarsson S, Jones B, Larsson K and Viring S (1980) Distribution of smalland medium-sized molecules within the genital tract of artificially inseminated gilts Journal of Reproduction and Fertility 59 453-457

Ellington JE, Ignotz GG, Varner DD, Marcusio RS, Mathison P and Ball BA (1993) In vitro interaction between oviduct epithelia and equine sperm Archives of Andrology 31 79-86

Fléchon JE and Hunter RHF (1981) Distribution of spermatozoa in the utero-tubal junction and isthmus of pigs, and their relationship with the luminal epithelium after mating Tissue and Cell 13 127-139

Grippo AA, Way AL and Killian GJ (1995) Effect of bovine ampullary and isthmic oviductal fluid on motility, acrosome reaction and fertility of bull spermatozoa Journal of Reproduction and Fertility $10557-64$

Hadek R (1958) Intraperitoneal insemination of the rabbit doe Proceedings of the Society for Experimental Biology and Medicine 99 39-40

Hafez ESE and Blandau RJ (1969) The Mammalian Oviduct. University of Chicago Press, Chicago, IL

Hancock JL (1961) Fertilisation in the pig Journal of Reproduction and Fertility 2 307-331

Harper MJK (1961a) The mechanisms involved in the movement of newly ovulated eggs through the ampulla of the rabbit Fallopian tube Journal of Reproduction and Fertility 2 522-524

Harper MJK (1961b) Egg movement through the ampullar region of the 
Fallopian tube of the rabbit Proceedings of 4th International Congress on Animal Reproduction, The Hague 375

Holtz W (1996) Die Zyklussteuerung beim Schwein - eine Standortbestimmung (Kurzmitteilung) Archiv für Tierzucht, Dummerstorf 39 447-454

Hunter RHF (1969) Capacitation in the golden hamster, with special reference to the influence of the uterine environment journal of Reproduction and Ferititity 20 223-237

Hunter RHF (1973) Polyspermic fertilisation in pigs after tubal deposition of excessive numbers of spermatozoa Journal of Experimental Zoology 183 57-64

Hunter RHF (1974) Chronological and cytological details of fertilisation and early embryonic development in the domestic pig, Sus scrofa. Anatomical Record 178 169-186

Hunter RHF (1977) Function and malfunction of the Fallopian tubes in relation to gametes, embryos and hormones European journal of Obstetrics Gynecology and Reproductive Biology 7 267-283

Hunter RHF (1978) Intraperitoneal insemination, sperm transport and capacitation in the pig Animal Reproduction Science 1 167-179

Hunter RHF (1981) Sperm transport and reservoirs in the pig oviduct in relation to the time of ovulation Journal of Reproduction and Fertility 63 109-117

Hunter RHF (1984) Pre-ovulatory arrest and peri-ovulatory redistribution of competent spermatozoa in the isthmus of the pig oviduct Journal of Reproduction and Fertility 72 203-211

Hunter RHF (1987a) Peri-ovulatory physiology of the oviduct, with special reference to progression, storage, and capacitation of spermatozoa. In New Horizons in Sperm Cell Research pp 31-45 Ed. H Mohri. Japan Sci. Soc. Press, Tokyo

Hunter RHF (1987b) The timing of capacitation in mammalian spermatozoa a reinterpretation Research in Reproduction 193-4

Hunter RHF (1988) The Fallopian Tubes: Their Role in Fertility and Infertility Springer-Verlag, Berlin, Heidelberg and New York

Hunter RHF (1990) Physiology of the Fallopian tubes, with special reference to gametes, embryos and microenvironments. In From Ovulation to Implantation pp 101-119 Eds JLH Evers and MJ Heineman. Excerpta Medica, International Congress Series No. 917

Hunter RHF (1995a) Ovarian endocrine control of sperm progression in the Fallopian tubes Oxford Reviews of Reproductive Biology 17 85-125

Hunter RHF (1995b) How, when and where do spermatozoa gain their fertilising ability in vivo? Reproduction in Domestic Animals 31 51-55

Hunter RHF (1996) Ovarian control of very low sperm/egg ratios at the commencement of mammalian fertilisation to avoid polyspermy Molecular Reproduction and Development 44 417-422

Hunter RHF (1997) Sperm dynamics in the female genital tract: interactions with Fallopian tube microenvironments. In Microscopy of Reproduction and Development: A Dynamic Approach pp 35-45 Ed. PM Motta. Antonio Delfino, Rome

Hunter RHF and Dziuk PJ (1968) Sperm penetration of pig eggs in relation to the timing of ovulation and insemination Journal of Reproduction and Fertility 15 199-208

Hunter RHF and Hall JP (1974) Capacitation of boar spermatozoa: synergism between uterine and tubal environments Journal of Experimental Zoology 188 203-214

Hunter RHF and Nichol R (1986) A preovulatory temperature gradient between the isthmus and ampulla of pig oviducts during the phase of sperm storage Journal of Reproduction and Fertility 77 599-606

Hunter RHF, Karagiannidis A and Mann T (1972) Fate of seminal plasma after intrauterine insemination in the pig Journal of Reproduction and Fertility 29 303-305

Hunter RHF, Holtz W and Herrmann $H$ (1978) Stabilising role of epididymal plasma in relation to the capacitation time of boar spermatozoa Animal Reproduction Science 1 161-166

Hunter RHF, Cook B and Poyser NL (1983) Regulation of oviduct function in pigs by local transfer of ovarian steroids and prostaglandins: a mechanism to influence sperm transport European Journal of Obstetrics Gynecology and Reproductive Biology 14 225-232
Hunter RHF, Fléchon B and Fléchon JE (1987) Pre- and peri-ovulatory distribution of viable spermatozoa in the pig oviduct: a scanning electron microscope study Tissue and Cell 19 423-436

Hunter RHF, Fléchon B and Fléchon JE (1991) Distribution, morphology and epithelial interactions of bovine spermatozoa in the oviduct before and after ovulation: a scanning electron microscopy study Tissue and Cell 23 641-656

Hunter RHF, Grondahl C, Greve T and Schmidt M (1997) Graafian follicles are cooler than neighbouring ovarian tissues and deep rectal temperatures Human Reproduction 1295-100

Nichol R, Hunter RHF, Gardner DK, Leese HJ and Cooke GM (1992) Concentrations of energy substrates in oviductal fluid and blood plasma of pigs during the peri-ovulatory period Journal of Reproduction and Fertility 96 699-707

Nichol R, Hunter RHF, de Lamirande E, Gagnon C and Cooke GM (1997) Motility of spermatozoa in hydrosalpingeal and follicular fluid of pigs Journal of Reproduction and Fertility 110 79-86

Noyes RW (1953) The fertilising capacity of spermatozoa Western Journal of Surgery Obstetrics and Gynecology 61 342-349

Oxenreider SL and Day BN (1965) Transport and cleavage of ova in swine Journal of Animal Science 24 413-417

Polge C (1978) Fertilisation in the pig and horse Journal of Reproduction and Fertility 54 461-470

Pollard JW, Plante C, King WA, Hansen PJ, Betteridge KJ and Suarez SS (1991) Fertilizing capacity of bovine sperm may be maintained by binding to oviductal epithelial cells Biology of Reproduction 44 102-107

Racey PA, Suzuki F and Lord Medway (1975) The relationship between stored spermatozoa and the oviductal epithelium in bats of the genus Tylonycteris. In The Biology of Spermatozoa pp 123-133 Eds ESE Hafez and C. Thibault. Karger, Basel

Raychoudhury SS, Suarez SS and Buhi WC (1993) Distribution of lectin binding sites in the oviducts of cycling and hormone-treated pigs journal of Experimental Zoology $265659-668$

Rowlands IW (1957) Insemination of the guinea pig by intraperitoneal injection Journal of Endocrinology 16 98-106

Rowlands IW (1958) Insemination by intraperitoneal injection Proceedings of the Society for the Study of Fertitity 10 150-157

Skjerven $O$ (1955) Conception in a heifer after deposition of semen in the abdominal cavity Fertility and Sterility 6 66-67

Smith TT and Yanagimachi R (1989) Capacitation status of hamster spermatozoa in the oviduct at various times after mating Journal of Reproduction and Fertility 86 255-261

Smith TT and Yanagimachi R (1990) The viability of hamster spermatozoa stored in the isthmus of the oviduct: the importance of sperm-epithelium contact for sperm survival Biology of Reproduction 42 450-457

Smith TT and Yanagimachi R (1991) Attachment and release of spermatozoa from the caudal isthmus of the hamster oviduct Journal of Reproduction and Fertility $91567-573$

Stalheim OHV, Gallagher JE and Deyoe BL (1975) Scanning electron microscopy of the bovine, porcine and caprine uterine tube (oviduct) American fournal of Veterinary Research 36 1069-1075

Suarez SS (1987) Sperm transport and motility in the mouse oviduct: observations in situ. Biology of Reproduction 36 203-210

Suarez SS, Redfern K, Raynor P, Martin F and Phillips DM (1991) Attachment of boar sperm to mucosal explants of oviduct in vitro: possible role in formation of a sperm reservoir Biology of Reproduction 44 998-1004

Thibault C (1959) Analyse de la fécondation de l'oeuf de la truie après accouplement ou insémination artificielle Annales de Zootechnie 8 165-177

Way AL, Schuler AM and Killian GJ (1997) Influence of bovine ampullary and isthmic oviductal fluid on sperm-egg binding and fertilization in vitro. Journal of Reproduction and Fertility 109 95-101

Wu ASH, Carlson SD and First NL (1976) Scanning electron microscopic study of the porcine oviduct and uterus fournal of Animal Science 42 804-809

Yanagimachi R (1994) Mammalian fertilisation. In The Physiology of Reproduction 2nd Edn pp 189-317 Eds E Knobil and J Neill. Raven Press, New York 